\title{
RADIOGRAPHIC AND HISTOLOGICAL APPEARANCES OF THE RAT LUNG AFTER INTRATRACHEAL INJECTION OF ROUGE $\left(\mathrm{Fe}_{2} \mathrm{O}_{3}\right)$
}

\author{
BY
}

\author{
H. E. HARDING
}

\section{From the Department of Pathology, Sheffield University}

The first published suggestion that some shadows in radiographs of lungs might be produced by iron oxide and not by fibrosis was made by Collis in 1923, but Fawcitt (1943) quotes letters exchanged between Thurston Holland and Collis in 1919 when the possibility was discussed. In 1936 Doig and McLaughlin gave the first account of the $x$-ray appearances of the lungs of electric-arc welders, and suggested that these appearances might be due to iron deposits. Recently McLaughlin, Barrie, Grout and Harding (1945) have reported on the condition of the lungs of silver polishers, suggesting that these workmen have no industrial disability and that the radiographic abnormalities in their lungs are the result of iron oxide deposition without attendant fibrosis. A brief review of the literature of iron pigmentation of the lung is also given. Since this last paper was written, the lungs of two more silver polishers have been examined and found to show similar pigmentation without fibrosis. Since then the Miners' Phthisis Bureau of South Africa (1944) report investigations on a native iron-ore miner whose radiograph at the end of 1937 showed a ' generalized small mottling throughout the fields of both lungs '; this man died from lobar pneumonia in 1939, and his lungs were found to have heavy deposits of haematite dust but no fibrosis. The report concludes that the " mottling observed in his radiograph was due entirely to deposits of haematite in the lung substance and not to fibrosis.'

There are few papers describing the effects of iron oxide on the lungs of experimental animals, and no reports of the production of radiographic appearances corresponding with the reticulation or nodulation found in man. There is, however, general agreement that iron oxide does not produce fibrosis under the varied experimental conditions used. It is not proposed to discuss here the early histological picture, which is well described in the guinea-pig by Carleton (1927) and by Haynes (1931). Naeslung (1937, 1938) used a number of dusts, mainly derived from iron ores, in inhalation experiments on rabbits, and found fibrosis in the lungs of only those animals which had inhaled a silicacontaining dust. He pictured the miliary accumu- lations of iron pigment, and noted that ' a number of animals amongst which pneumoconiosis or silicosis was obvious on autopsy had shown no alterations of the lungs when $x$-rayed at the conclusion of the dust exposure.' In a further experiment (Naeslund 1940), two rabbits inhaled a mixture of $\mathrm{Fe}_{2} \mathrm{O}_{3}$ and $\mathrm{Fe}_{2} \mathrm{O}_{5}$ for six months; when they were killed three months later the lungs are stated to have shown a slight general fibrotic change but no nodular fibrosis. Harrold, Meek and McCord (1940) exposed rabbits and rats to welding fumes; they noted that early diffuse pigmentation became more nodular with time, and that "no fibrotic changes or other pathology of a permanent nature ascribable to metallic fumes have been observed.' They also said that ' $\mathrm{x}$-ray examinations made on intact animals and on extirpated lungs yielded no positive results.' Gardner and McCrum (1942) studied x-ray films of the distended lungs of 3 cavies exposed to arc-welding fumes for 10 months and then kept in a normal atmosphere for another 3 months. No pictures were given but they stated ' to our surprise it was possible to distinguish their films from that of a normal animal's lungs. The great number of fine particles of high molecular weight cast a diffuse shadow which gave the lung fields a very fine grainy appearance.' They found that the response to the metallic particles in the fume was that to inert foreign particles: 'it consisted of simple phagocytosis without demonstrable effect upon the dust cells and without subsequent proliferation of fixed tissues.' I agree with this statement.

\section{Method}

The rouge was a sample of the material used in the polishing of silver and was almost pure $\mathrm{Fe}_{2} \mathrm{O}_{3}$. Nine white rats, approximately 3 months old, were anaesthetized with ether and $0.5-1 \mathrm{ml}$. of a sterile 5 per cent. suspension of rouge in physiological saline was injected into the trachea by a method similar to that described by Kettle and Hilton (1932). A variable quantity of rouge was returned almost immediately via the nostrils so that some animals retained only small amounts in their lungs. Five 


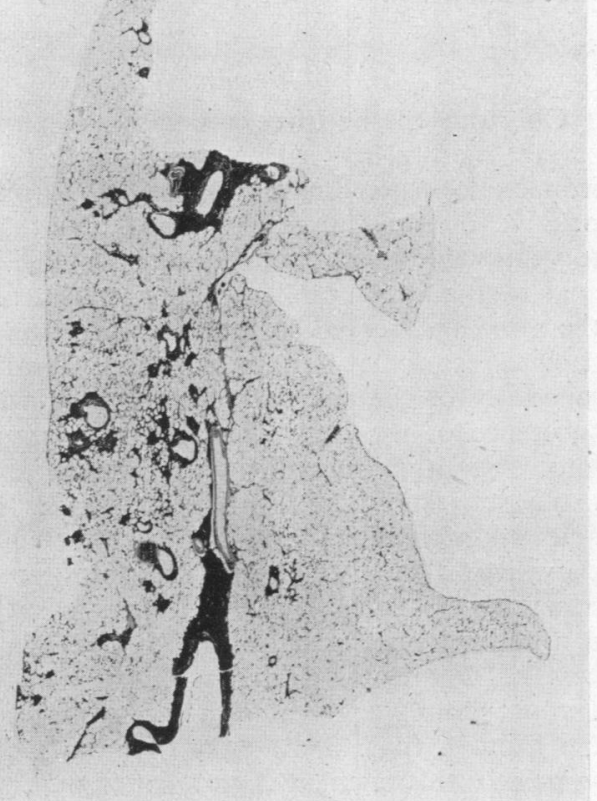

Fig. 1.-Section of R.L.L. of treated rat. (H. and E. $\times 5$.)

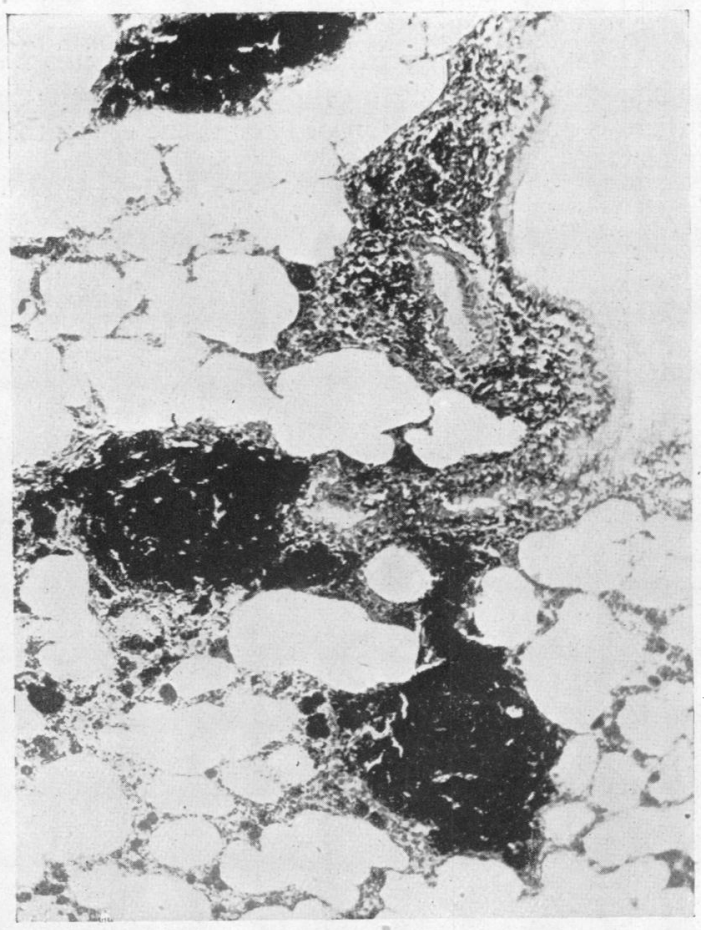

FIG. 3.-Aggregates of dust-laden phagocytes close to large bronchus. (H. and $E_{0} \times 85$.)

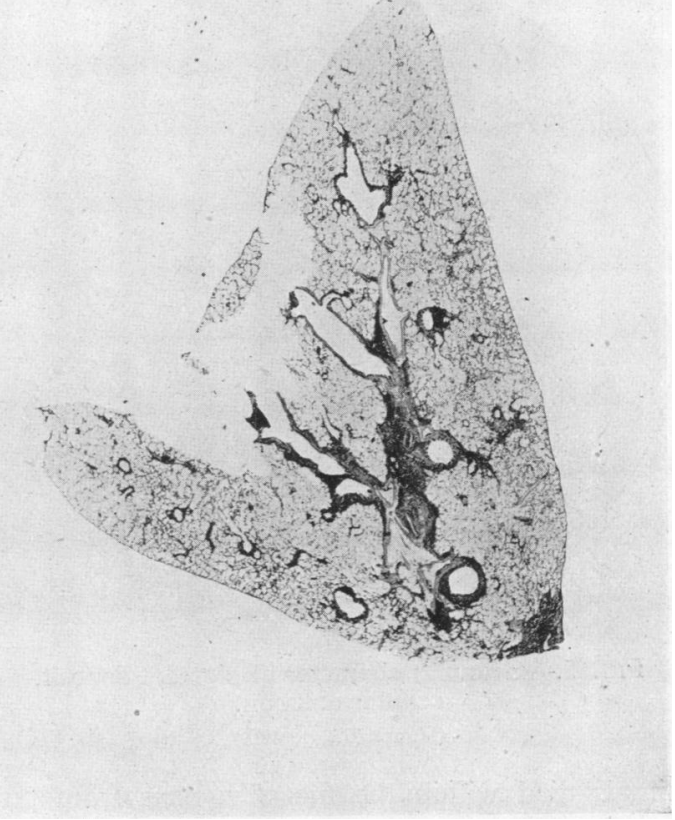

Fig. 2.-R.L.L. of control rat. (H. and E. $\times 5$.)

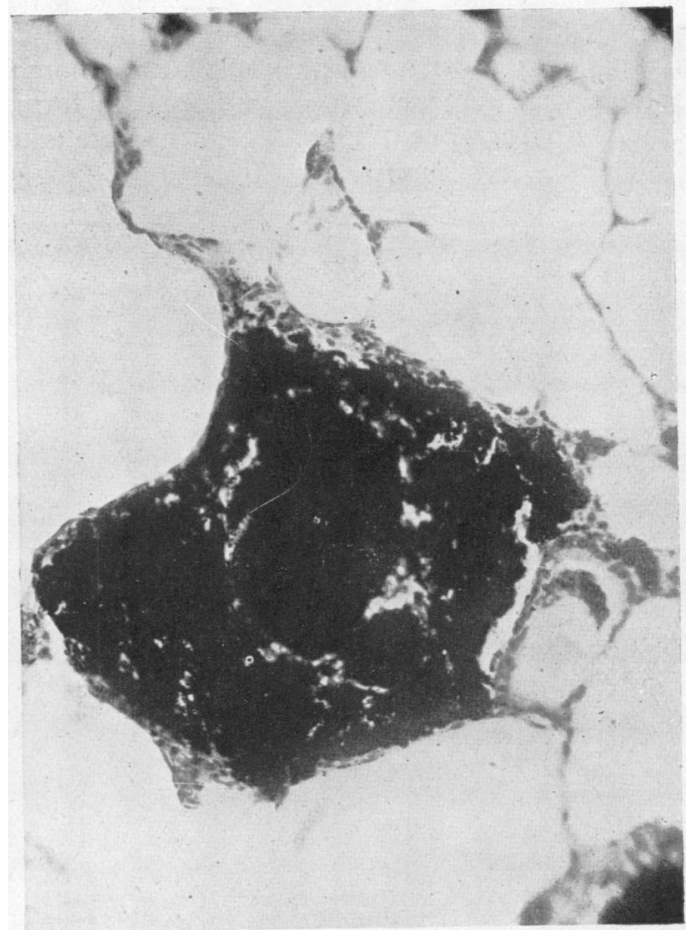

Fig. 4.-Aggregate beside a bronchiole.

(H. and E. $\times 200$.) 


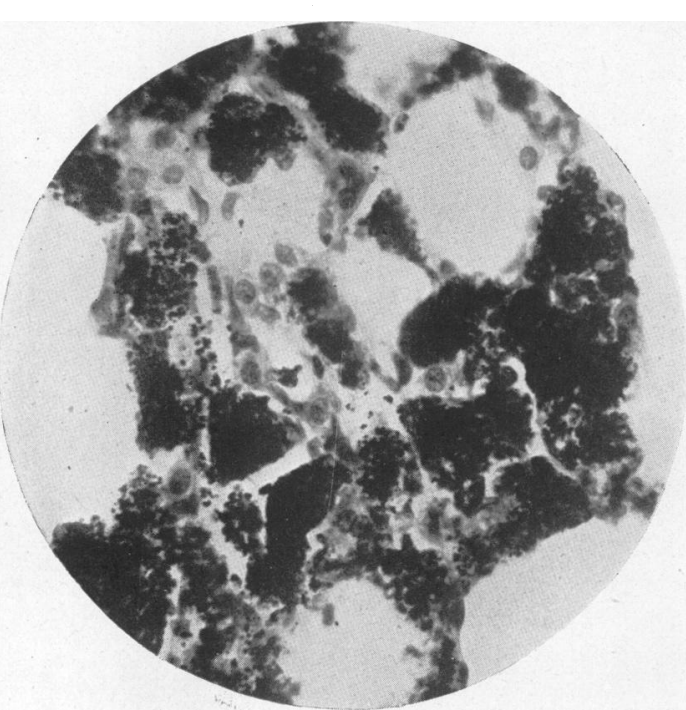

FIG. 5.-Granular character of pigment deposit, cellular reaction.

(H. and E. $\times 400$.)

animals died within the first few days from pulmonary inflammations; it appears possible, as suggested by Carleton (1927) and by Haynes (1931), that rouge is mildly irritant. in this early stage, certainly it collects in relatively greater amounts in inflamed areas of lung as was noted by Barclay, Franklin and Prichard (1940). Those animals that survived beyond the first few days appeared completely healthy. After 32-37 weeks the survivors were anaesthetized with ether, the trachea tied in the neck and the great vessels in the abdomen cut as rapidly as possible. The trachea and thoracic contents were removed whole and fixed in formol saline. Radiographs of these specimens were taken

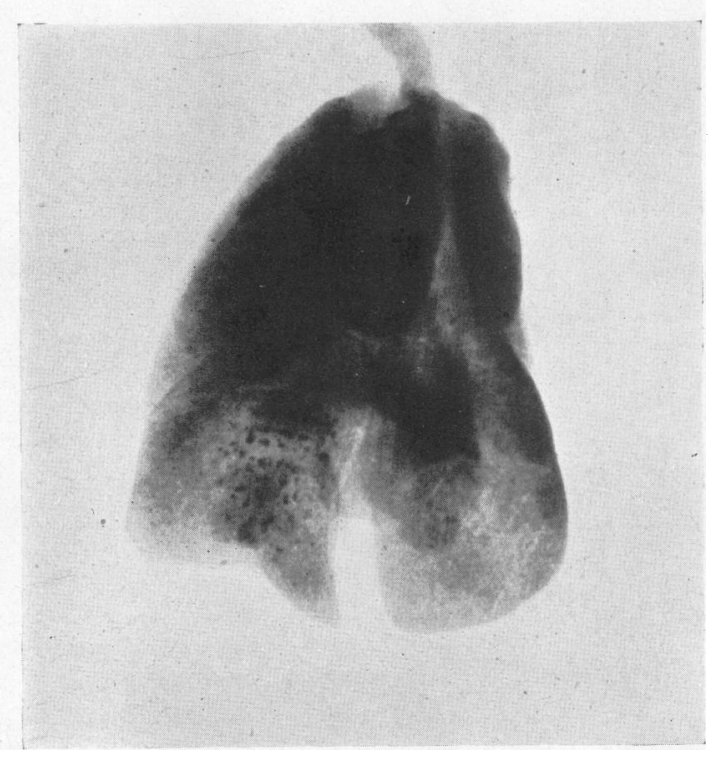

FIG. 6.-Radiograph of thoracic contents of treated animal. (Positive print $\times 2$.) a few days later, and histological preparations were made after this.

\section{Results}

Only one of the three animals that survived for several months showed any appreciable amount of iron oxide in its lungs; this animal furnished the positive evidence presented here, the other two, together with several animals similarly injected with coal-dust and a number of untreated animals of the same age, served as controls. This one animal showed scarlet red dots on the pleural surface especially of the right lower lobe, and within the substance of the lung when it was eventually cut into. No other animal showed anything similar.

No suggestion of any fibrosis of the lung was detected macroscopically, and sections (figs. 1, 2) show that there is none microscopically: in fact, some of the control animals show slightly more connective tissue around the bronchi and large vessels. Pigment is found within phagocytic cells that are mainly aggregated in lymph spaces close to the bronchi (figs. 3,4 ) or within the pleura. In some cells this pigment is granular (fig, 5), but most of these cells are so densely packed that no detail can be resolved. The pigment appears black with transmitted light; when stained with potassium ferro-cyanide and $\mathrm{HCl}$ in the ordinary way or by the modified technique of Gömöri (1936) only a few granules show a blue colour (or, rather, a blue halo), the denser masses remain black. The pigment is still present after incineration of sections at $500^{\circ} \mathrm{C}$., and when viewed by reflected light appears bright red.

Around these aggregates there is some increase of phagocytic cells but I cannot satisfy myself that there is any proliferation of fixed tissue cells; there

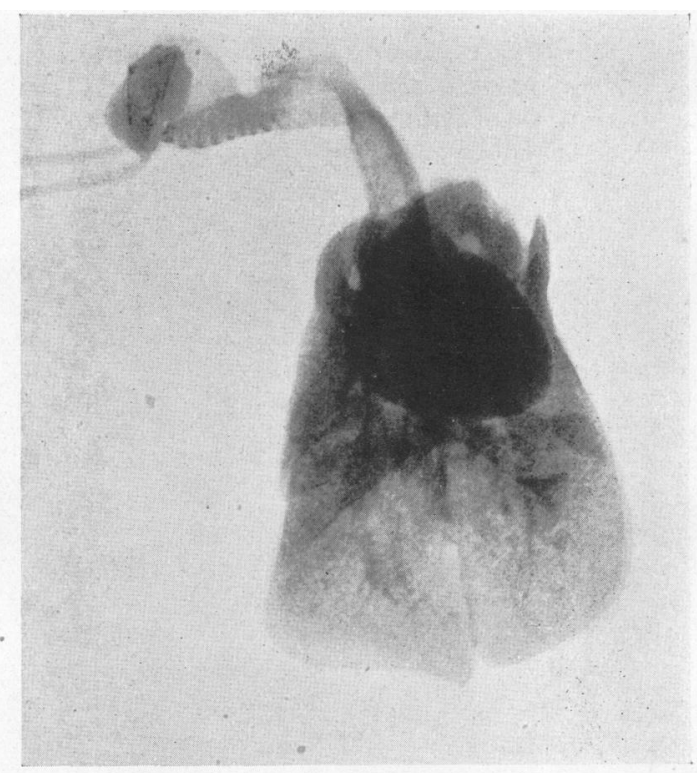

Fig. 7.-Radiograph of control animal. (Positive print $\times 2$.) 
is no increase in fibrous tissue demonstrable by staining for collagen or for reticulin fibrils.

Radiographs of the lungs (figs. 6 and 7) were examined by Dr. J. L. A. Grout, who reports that ' very fine dense opacities are scattered over one of the lobes apparently near the surface. A careful examination with a lens shows a general intensification of the markings of the lungs, with some very fine and less dense opacities, which give a stippled appearance to the lobes.' The dense opacities almost certainly represent the subpleural aggregates, a 'pleural drift' of particles of dust in the lungs has been noted by several investigators. The stippling results from the numerous small aggregates in lymph spaces alongside bronchi; it is not unlike a miniature 'snow storm,' and I take it to correspond in miniature to 'nodulation' in a radiograph of a human lung.

\section{Discussion}

The radiographical appearances, which are comparable with the reticulation or nodulation seen in films of human lungs in many industrial diseases or conditions, here obviously result solely from the aggregates of iron oxide. Fibrosis plays no part in the production of the radiographic picture, since, in fact, under the conditions of this experiment iron oxide deposits do not lead to any fibrosis. Strictly comparable appearances may be found in electricarc welders (Doig and McLaughlin, 1936 ; Enzer and Sanders, 1938), acetylene or carbon-arc welders, in silver polishers (McLaughlin et al. 1945), and in persons engaged in the manufacture of iron oxides (McLaughlin, personal communication). Iron oxide is responsible in part for the radiographical changes in the lungs of such workers as iron-ore miners (Fawcitt, 1943), steel fettlers, moulders, boiler scalers (Harding, Tod and McLaughlin, 1944): in these workers fibrosis due to silica also comes into the picture. It is obviously important to recognize that reticulation or nodulation in a radiograph may be due to deposits of iron oxide or to some other metallic oxide, e.g. baryta (Pendergrass, 1938; Preti and Talini, 1939), and is not necessarily evidence of a disease.

The difficulty of differentiating between carbon and iron oxide pigments in sections of lung has been noted previously (McLaughlin et al. 1945). In ordinary sections stained with haematoxylin and eosin both pigments appear as black masses enclosed within phagocytic cells. The prussian blue reaction, although it works well with haemosiderin, is of little use here-even if the masses should become coloured they still remain opaque and black to transmitted light. This was recognized by Stewart and Faulds (1934) in their description of the siderosilicosis of iron-ore workers. The only satisfactory method is to incinerate duplicate sections at $500^{\circ} \mathrm{C}$. and view them by reflected light; the bright red oxide of iron then shows clearly, while carbon pigment has disappeared. Since using this technique I have been surprised at the large amount of what was taken to be carbon pigment in human lungs from many sources that now turns out to be iron or iron oxide.

\section{Summary}

Radiographic stippling or fine nodulation of the lungs has been produced in the rat by intratracheal injection of rouge $\left(\mathrm{Fe}_{2} \mathrm{O}_{3}\right)$. No fibrosis was detectable in these lungs as a result of the presence of iron oxide for some eight months.

\section{Acknowledgments}

Much valuable stimulation and advice has been received from Dr. A. I. G. McLaughlin of H.M. Medical Inspectorate of Factories, who also provided the sample of rouge. Dr. J. L. A. Grout's advice and reports on radiology have been essential. The radiographs were taken by Mr. A. O. Watson, and the enlarged positive prints made by Mr. G. S. English. The photomicrographs were made by Mr. A. W. Collins.

\section{REFERENCES}

Barclay, A. E., Franklin, K. J., and Prichard, M. M. C. (1940), Brit. J. Radiol., 13, 410

Carleton, H. M.(1927). J. Hyg., Camb., 16, 227.

Collis, E. L. (1923). Proc. roy. Soc. Med.,16, 85

Doig, A. T., and McLaughlin, A. I. G. (1936). Lancet, 1, 771.

Enzer, N., and Sander, O. A. (1938). J. industr. Hyg., 20, 333.

Fawcitt, R. (1943). Brit. J. Radiol., 16, 323.

Gardner, L. U., and McCrum, D. S.'(1942). J. industr. Hyg., 24, 173

Gardner, L. U., and Mëri, G. (1936). Amer. J. Path., 12, 655.

Harding, H. E., Tod, D. L. M., and McLaughlin, A. I. G. (1944) Brit. J. industr. Med., 1, 247 .

Brit. . C., Meek, S. F., and McCord, C. P. (1940). J. industr. Hyg. 22, 347 .

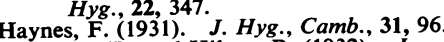

Kettle, E. H., and Hilton, R. (1932). Lancet, 1, 1190.

McLaughlin, A. I. G., Barrie, H. J., Grout, J. L. A., and Harding, H. E. (1945). In the press.

Naesland, C. (1937). Nord. hyg. Tidskr., 18, 139.

Naesland, C. (1938). J. industr. Hyg., 20, 435.

- (1940). Ibid., 22, 1 .

Pendergrass, E. P. (1938). In Silicosis and Asbestosis (by A. J. Lanza), Oxford Univ. Press, 1938, p. 137.

Preti, L., and Talini, P. C. (1939). Bericht. viii Internat. Kongress Unfallmed. $u$. Berusfskrank. 1938 (G. Thieme, Leipzig), 2, 963

Rept. Miners' Phthisis Bureau Union S. Africa for 3 years ended 31 July 1941 (1944). Pretoria.

Stewart, M. J., and Faulds, J. S. (1934). J. Path. Bact., 39, 233. 